\title{
Experimental Studies on Fuel Spray Characteristics of Pressure-Swirl Atomizer and Air-Blast Atomizer
}

\author{
WANG Kaixing ${ }^{1,2}$, FAN Xiongjie ${ }^{1,2}$, LIU Fuqiang ${ }^{1,2^{*}}$, LIU Cunxi ${ }^{1,2}$, LU Haitao ${ }^{1,2}$, XU Gang ${ }^{1,2 *}$ \\ 1. Key Laboratory of Light-duty Gas-turbine, Institute of Engineering Thermophysics, Chinese Academy of Sciences, \\ Beijing 100190, China \\ 2. University of Chinese Academy of Sciences, Beijing 100049, China \\ (C) Science Press, Institute of Engineering Thermophysics, CAS and Springer-Verlag GmbH Germany, part of Springer \\ Nature 2021
}

Erratum to: Journal of Thermal Science Vol.30, No.1 (2021) 729-741

https://doi.org/10.1007/s11630-021-1320-z Article ID: 1003-2169(2021)02-0729-13

The original article has been corrected.

\begin{abstract}
It was written:
Acknowledgments

This work was supported by National Science and Technology Major Project (Project No. 2017-III-0007 and No. 2017-III-0002) and Youth Innovation Promotion Association, Chinese Academy of Science (No. 2019147).

It is written:

Acknowledgments

This work was supported by National Science and Technology Major Project (Project No. 2017-III-0007-0032 and No. 2017-III-0002-0026) and Youth Innovation Promotion Association, Chinese Academy of Science (No. 2019147).
\end{abstract}

The online version of the original article can be found at https://oi.org/10.1007/s11630-021-1320-z 